\title{
Do generalized scaling laws exist for species abundance distribution in mountains?
}

\author{
Yuxin Zhang, Keming Ma, Madhur Anand and Bojie Fu
}

Zhang, Y., Ma, K., Anand, M. and Fu, B. 2006. Do generalized scaling laws exist for species abundance distribution in mountains? - Oikos 115: 81-88.

\begin{abstract}
Knowing the global pattern of species diversity is a central goal of the science of ecology, and scaling laws can be useful for analysis of cross-scale biodiversity patterns. An elevational gradient in a warm temperate zone of the Donglingshan mountains (China) is used to test the scaling laws of species abundance distribution using multifractal analysis. We show that the power law scaling relationship holds for not just the classical SAR (species-area relationship for richness), but also for Shannon and Simpson diversity. In fact, we find power-laws in the generalized species abundance distribution at all stratal levels of the forest (trees, shrubs and herbs). The fact that these laws exist across a heterogeneous landscape representing a strong bioclimatic gradient suggests that biodiversity scaling laws may be more robust than previously thought.
\end{abstract}

Y. Zhang, K.Ma (mkm@ rcees.ac.cn) and B. Fu, State Key Lab of Systems Ecology, Research Center for Eco-Environmental Sciences, Chinese Academy of Sciences, CN100085 Beijing, PR China. YZ also at: Graduate School of Chinese Academy of Sciences, CN-100039 Beijing 100039, PR China. - YZ and M. Anand, Dept of Biology, Laurentian Univ., 935 Ramsey Lake Road, Sudbury, Ontario, Canada, P3E 2 C6. Present address for MA: Dept of Environmental Biology, Univ. of Guelph, Guelph, Ontario, Canada, N1G 2 W1.

Developing a universal theory of biodiversity, which involves scaling laws, is one of the greatest challenges to ecologists (Hubbell 2001, Pachepsky et al. 2001), because species are heterogeneously distributed across landscapes and are organized within distinct communities or assemblages (Gaston 1994, 2000) across several scales (Auerbach and Shmida 1987, Lyons and Willig 1999). Finding general laws to describe the complex pattern of species distribution and abundance is important because these can provide information about species richness, species extinction probability, reserve design, species coexistence and resources partition processes (Gaston 1994). If scaling laws exist, this may also imply that there could be some simple physical governing mechanisms explaining the pattern (Brown et al. 2002). This may reveal further laws for how ecological communities are assembled on local-to-landscape spatial scales, and can be used as benchmark criteria for evaluating the performance of mechanistic simulation models that attempt to recreate species-area relationship (SAR) and patterns of relative species abundance (Borda-de-Água et al. 2002, Harte et al. 2005).

A scaling law is the mathematical relationship that describes any size (scale)-dependent variation (Niklas 1994). The most commonly used scaling law is the power-law. Such a power-law pattern is everywhere in ecology, from organism to landscape levels (Milne 1991, Gaston and Blackburn 2000). In community ecology, a well-known example is SAR (Arrhenius 1921):

$\mathrm{S}(\mathrm{A})=\mathrm{cA}$ 
$\mathrm{S}(\mathrm{A})$ is species richness in area $\mathrm{A} ; \mathrm{z}$ is the scaling exponent (easily related to a fractal dimension); and $\mathrm{c}$ is a constant. This law can help determine the "minimal area" of sampling, characterize community structure, estimate species richness, measure disturbance effect, and to define the appropriate size of reserves and natural areas in conservation biology (He and Legendre 1996). This scaling law is considered one of the few robust laws of ecology. It relates to scale invariant patterns of spatial aggregation of species (Harte et al. 1999a), and reveals the fractal nature of community or ecological assemblages (Harte et al. 1999a, Borda-de-Água et al. 2002, Ostling et al. 2003, 2004).

SAR is only a special scenario to describe the relationship between area and species abundance distribution, for it only takes into account the presence/ absence of species, not the relative abundance (Preston 1962, May 1975). As a result, biodiversity in this relation is measured as species richness. However, it is well known (Rényi 1970, Hill 1973, Pielou 1975) that species richness is simply one measure of a family of diversity measures that can be related to each other by Rényi's generalized entropy function:

$\mathrm{H}_{\alpha}=\frac{1}{1-\alpha} \log \sum_{\mathrm{i}=1}^{\mathrm{s}} \mathrm{p}_{\mathrm{i}}^{\alpha}$

In this relation, most classical diversity measures are special cases of Rényi's generalized entropy. For example, Shannon is the case of $\alpha$ approaching 1, Simpson's index is the case of $\alpha=2$, and species richness is $\alpha=0$. Thus, the SAR relation can easily be generalized as follows:

$\mathrm{H}_{\alpha}(\mathrm{A})=\mathrm{c}_{\alpha} \mathrm{A}^{\mathrm{z \alpha}}$

If the scaling relationships are examined along the spectrum of $\alpha$, then the analysis becomes a multifractal one.

Borda-de-Água et al. (2002) carried out such a multifractal analysis using the Barro Colorado Island (BCI) 50 ha tropical forest plot data. Although this data did not provide a very good fit (only the conventional SAR relation is fit well, but not the multifractal distribution), they suggest that generalized scaling laws may exist for species abundance distribution and should be more widely tested. We believe that the poor fit for the BCI data may have to do with the fact that this ecosystem experiences little environmental heterogeneity due to, for example, topographic effects. The BCI plot is located in a wet lowland area with tropical climate and $38 \mathrm{~m}$ in topography variation (Condit et al. 2000). Indeed Plotkin et al. (2000) found that the SAR relation did not hold for tropical forests below the scale of $50 \mathrm{ha}$. The objective of our study is to examine the broader implications of scaling laws of species diversity. We focus attention on mountain ecosystems which occupy 24 percent of the Earth's land surface (Kapos et al. 2000) and have recently been identified as understudied hotspots of biodiversity. The compression of climatic zones and complicated topography along elevational gradients causes mountain to be analogous to highly diverse heterogeneous land surfaces (Körner 2000, Körner et al. 2001) and a suitable model to study scale effects (Rahbek 2005). To our knowledge, no testing of the existence of generalized scaling laws has occurred in mountain ecosystems. If such laws exist in mountains, our work would accomplish dual-purpose both provide evidence to Borda-de-Água et al.'s hypothesis and improve the generality of their hypothesis to a wide range of ecosystems.

\section{Methods}

\section{Study area}

Donglingshan Mountain is an extension of Xiaowutaishan Mountains and belongs to the broader Taihangshan Mountains, $100 \mathrm{~km}$ northwest from Beijing City, China. The study area, the Beijing Forest Ecosystem Research Station of the Chinese Academy of Sciences, is located at $40^{\circ} 00^{\prime}-40^{\circ} 03^{\prime} \mathrm{N}$ and $115^{\circ} 26^{\prime}-115^{\circ} 30^{\prime} \mathrm{E}$. Soil type of the area is brown soil classified as Eutric cambisol (FAO-UNESCO 1988). The area has a typical warm temperate continental monsoon climate with average annual precipitation of $500-650 \mathrm{~mm}$. The mean annual temperature is $5-10^{\circ} \mathrm{C}$. The altitude of most of the area is more than $1000 \mathrm{~m}$ above sea level, the highest peak being at $2303 \mathrm{~m}$. The zonal vegetation of the Donglingshan Mountain region is highly heterogeneous warm temperate zone deciduous broadleaved forest (Chen 1997), including mainly oaks (Quercus spp.), mixed species (e.g. Tilia spp., Ulmus spp., Acer spp., Juglans mandshurica and Fraxinus rhynchophylla etc.), birches (Betula spp.) and poplar (Populus davidiana). There are also some conifers and some shrubs (e.g. Prunus spp., Vitex negundo var. hetertophylla, etc.).

\section{Sampling methods}

Ten transects are set up from the foot to the top of every western slope in the study area to compose a continuous altitude gradient $(1020 \mathrm{~m}-1770 \mathrm{~m})$, which completely overlaps the distribution range of Quercus liaotungensis in the study area. The width of each transect is $10 \mathrm{~m}$, and the length range of each transect is from $80 \mathrm{~m}$ to $200 \mathrm{~m}$, depending on the altitude range and slope degree of each slope. We however ignored the insignificant slope and slope degree effects on the spatial distribution of species, so all transects merged into a single transect 1190 meters long and consisting of 119 quadrats, each $10 \times 10 \mathrm{~m}^{2}$. In each quadrat, all the individuals 
of tree species $(\mathrm{DBH} \geq 2.0 \mathrm{~cm}$ ) were identified and measured for breast-height diameter, crown diameter, and height for tree layer record. For the shrub layer, each species (including tree species with DBH $<2.0 \mathrm{~cm}$ ) were identified and measured for abundance (number of individuals), coverage, and height. Within each quadrat, three sub-quadrats $(1 \times 1 \mathrm{~m})$ were randomly selected for the inventory of herbaceous vegetation (herb layer); the coverage, height and abundance (number of individuals) were recorded for each herbaceous species. We selected 96 continuous quadrats (altitude range between $1110 \mathrm{~m}$ to $1730 \mathrm{~m}$ ) for Rényi dimension calculating, and treat tree layer, shrub layer, and herb layer separately in order to be able to compare our results to those of other studies, some of which only worked with trees species.

\section{Multifractal analysis: Rényi dimensions}

\section{Theory background}

To implement multifractal analysis of a distribution supported on an interval $\mathrm{J}=[\mathrm{A}, \mathrm{B}]$, a set of different grids with cells of $\mathbf{J}$ with equal size is required, and scaling down is the common used method (Peitgen et al. 1992, Harte 2001), for example, cells of equal size $\delta$ in the successive partition of J. At each cell size $\delta, \mathrm{N}(\delta)=$ $\mathrm{J} / \delta$ is the number of cells, and $\mathrm{u}_{\mathrm{i}}(\delta)(\mathrm{i}=1,2, \ldots, \mathrm{N}(\delta))$ is the respective measure which can be found from available data. Rényi dimensions, D(q), also called generalized dimensions and the method of moments of multifractal analysis, may be computed through parameter q by (Rényi 1970, Hentschel and Procaccia 1983):

$\mathrm{D}_{\mathrm{q}}=\lim _{\delta \rightarrow 0} \frac{1}{\mathrm{q}-1} \frac{\log \left[\sum_{\mathrm{i}=1}^{\mathrm{N}(\delta)} \mu_{\mathrm{i}}(\delta)^{\mathrm{q}}\right]}{\log (\delta)} \mathrm{q} \neq 1$

$\mathrm{D}_{1}=\lim _{\delta \rightarrow 0} \frac{\sum_{\mathrm{i}=1}^{\mathrm{N}(\delta)} \mu_{\mathrm{i}}(\delta) \log \left(\mu_{\mathrm{i}}(\delta)\right)}{\log (\delta)} \quad \mathrm{q}=1$

Parameter $\mathrm{q}$ acts as a scanning tool scrutinizing the smaller and larger values of the measure $\mu_{\mathrm{i}}(\delta)$ on the support (Kravchenko et al. 1999). For $\mathrm{q} \gg 1$, regions with a high degree of concentration are amplified, while regions with a small degree of concentration are magnified for $\mathrm{q}<<-1$ (Montero 2005).

\section{Use of Rényi dimension to analysis species abundance distribution}

In our case, a set of different grids with rectangular cells of size $\delta$ was used to partition the study area (transect). Cell $\mathrm{i}$ of size $\delta$ was characterized by a series of relative species abundance values of the species occupied in it, $\mathrm{u}_{\mathrm{ij}}(\delta)\left(\mathrm{j}=1,2,3, \ldots \mathrm{N}_{\mathrm{i}}\right.$, where $\mathrm{N}_{\mathrm{i}}$ is the number of species of cell i). Ten cell sizes were considered in the study, $10 \times$ $10 \mathrm{~m}, 20 \times 10 \mathrm{~m}, \ldots, 320 \times 10 \mathrm{~m}$ with the total number of cells $(\mathrm{N}(\delta))$ in each transect being $96,48, \ldots, 3$, respectively (Fig. 1). The relative species abundance $\mu_{\mathrm{ij}}(\delta)$ is calculated by the formula:

$\mu_{\mathrm{ij}}(\delta)=\left[\frac{\mathrm{h}_{\mathrm{ij}}(\delta)}{\mathrm{th}_{\mathrm{i}}}+\frac{\mathrm{c}_{\mathrm{ij}}(\delta)}{\mathrm{tc}_{\mathrm{i}}}+\frac{\mathrm{a}_{\mathrm{ij}}(\delta)}{\mathrm{ta}_{\mathrm{i}}}\right] / 3$

where $\mathrm{h}_{\mathrm{ij}}(\delta), \mathrm{c}_{\mathrm{ij}}(\delta)$, and $\mathrm{a}_{\mathrm{ij}}(\delta)$ are the sum of the height, coverage and number of species $j$ in the cell $i$ with the cell size $\delta ; \mathrm{th}_{\mathrm{i}}, \mathrm{tc}_{\mathrm{i}}$, and $\mathrm{ta}_{\mathrm{i}}$ are the total value of the height, coverage, and number of all species in cell i, respectively. Equation (3) is an expression of the importance value (IV) of a species in a community (or ecological assemblage), used mainly for plant communities (Alatalo 1981). Relative abundance is a measure of relative importance of a species in community, so IV is one reasonable candidate for relative abundance measurers. By including height and cover, this equation takes the size variance of individuals into consideration.

Following Borda-de-Água et al. (2002), which we highly recommend for more details, the method of moments is briefly described here. For a given cell $\mathrm{i}$ with size $\delta$, the species number is $\mathrm{N}_{\mathrm{i}}$, and the relative abundance of each species is $\mathrm{u}_{\mathrm{ij}}(\delta)\left(\mathrm{j}=1,2, \ldots, \mathrm{N}_{\mathrm{i}}\right)$ is considered. In order to give a solution of $\mathrm{D}_{\mathrm{q}}$, another formula which can be derived from Eq. (1), (2) and (3) is introduced:

$\underset{1110 \mathrm{~m} \quad \text { altitude }}{\stackrel{1735 \mathrm{~m}}{\longrightarrow}}$

(a) $\delta=10 \times 10 \mathrm{~m} \mathrm{~N}(\delta)=96$

(b) $\delta=20 \mathrm{~m} \times 10 \mathrm{~m} \mathrm{~N}(\delta)=48$

\begin{tabular}{c|c|c|c|}
\hline & I & । \\
(c) $\delta=30 \times 10 \mathrm{~m} \mathrm{~N}(\delta)=32$
\end{tabular}

(d) $\delta=40 \times 10 \mathrm{~m} \mathrm{~N}(\delta)=24$

$\frac{1}{(e) \delta=60 \times 10 \mathrm{~m} \mathrm{~N}(\delta)=16}$

(f) $\delta=80 \times 10 \mathrm{~m} \mathrm{~N}(\delta)=12$

(g) $\delta=120 \times 10 \mathrm{~m} \mathrm{~N}(\delta)=8$

(h) $\delta=160 \times 10 \mathrm{~m} \mathrm{~N}(\delta)=6$

(i) $\delta=240 \times 10 \mathrm{~m} \mathrm{~N}(\delta)=4$

(j) $\delta=320 \times 10 \mathrm{~m} \mathrm{~N}(\delta)=3$

Fig. 1. Ten sampling sizes used to partitioning the transect, ranging from (a) $10 \times 10 \mathrm{~m}$ to (j) $320 \times 10 \mathrm{~m}$. For each one, we show the sampling size, $\delta$, the total number of the cells in the transect, $\mathrm{N}(\delta)$. The altitude range is from $1110 \mathrm{~m}$ to $1735 \mathrm{~m}$. 


$$
I_{\mathrm{q}}(\delta)=\left\{\begin{array}{c}
\frac{1}{\mathrm{q}-1} \log \left[\frac{\sum_{\mathrm{i}=1}^{\mathrm{N}(\delta)} \sum_{\mathrm{j}=1}^{\mathrm{N}}(\delta)}{\mathrm{N}(\delta)}\right] \quad \mathrm{q} \neq 1 \\
-\left[\frac{\sum_{\mathrm{i}=1}^{\mathrm{N}(\delta)} \sum_{\mathrm{j}=1}^{\mathrm{N}_{\mathrm{i}}} \mu_{\mathrm{ij}}(\delta) \log \left[\mu_{\mathrm{ji}}(\delta)\right]}{\mathrm{N}(\delta)}\right] \quad \mathrm{q}=1
\end{array}\right.
$$

where $\mathrm{I}_{\mathrm{q}}(\delta)$ called Rényi information. Equation (4) is the average value of Rényi information for all cells with size $\delta$ in whole transect (Borda-de-Água et al. 2002).

The estimation of the fractal dimensions is done as follows: Change the cell size $\delta$, and calculate a series $\mathrm{I}_{\mathrm{q}}(\delta)$, then plots $\log (\delta)$ against $\mathrm{I}_{\mathrm{q}}(\delta)$. The dimensions $\mathrm{D}_{\mathrm{q}}$ are the absolute value of the slope of the least square linear regression fitting of $\log (\delta)-\mathrm{I}_{\mathrm{q}}(\delta)$ (Hentschel and Procaccia 1983). Coefficients of determination and significant p-values of those fits should be obtained. This process is repeated for $\mathrm{q}$ ranging from -10 to 10 in increments of 0.5. Plotting $\mathrm{q}$ against $\mathrm{D}_{\mathrm{q}}$, gives the Rényi spectra. Each point in the Rényi spectra is the scaling exponent of a possible diversity-area power-law relationship $(q=0,1,2$ correspond to species richness, Shannon and Simpson diversity indices respectively). For more details on generalized entropy, please see Hill (1973) and Orlóci (1991).

$\mathrm{D}_{0}, \mathrm{D}_{1}, \mathrm{D}_{2}$ are the most often used Rényi dimensions (Peitgen et al. 1992). $\mathrm{D}_{0}$ is called box-counting dimension or capacity dimension, because it represents the dimension of the set of sizes with non-zero relative volume, and it is represents the maximum value of the spectrum. $D_{1}$ is the entropy dimension of the measure and gauges the scaling in the concentration of the measure by taking into account the abundance measures in each cell. $\mathrm{D}_{2}$ is the correlation dimension. $\mathrm{D}_{0}, \mathrm{D}_{1}, \mathrm{D}_{2}$ are also the scaling exponent of species richness, Shannon diversity index, and Simpson diversity index respectively (Borda-de-Água et al. 2002). $\mathrm{D}_{1} / \mathrm{D}_{0}$ is used to quantify the dispersion of the measure over the set of cell sizes (Caniego et al. 2003). Values of $D_{1} / D_{0}$ close to 1 will indicate sets with similar dimensions, i.e. abundance measures dispersed over the set of cell sizes, while values close to 0 will be found in measures (e.g. abundances) with most of the measure (e.g. abundance) concentrated in a small region of the set of sizes (Montero 2005).

\section{Results}

Figure 2 shows the rank-abundance curve of species abundance distribution for the three forest layers. We select five sampling cell sizes $(\delta)$ as demonstration, $\delta=20 \times 10 \mathrm{~m}, 40 \times 10 \mathrm{~m}, 80 \times 10 \mathrm{~m}, 160 \times 10 \mathrm{~m}$ and $320 \times 10 \mathrm{~m}$ respectively. Rank-abundance curves have similar shapes with increasing area (sampling size) in the
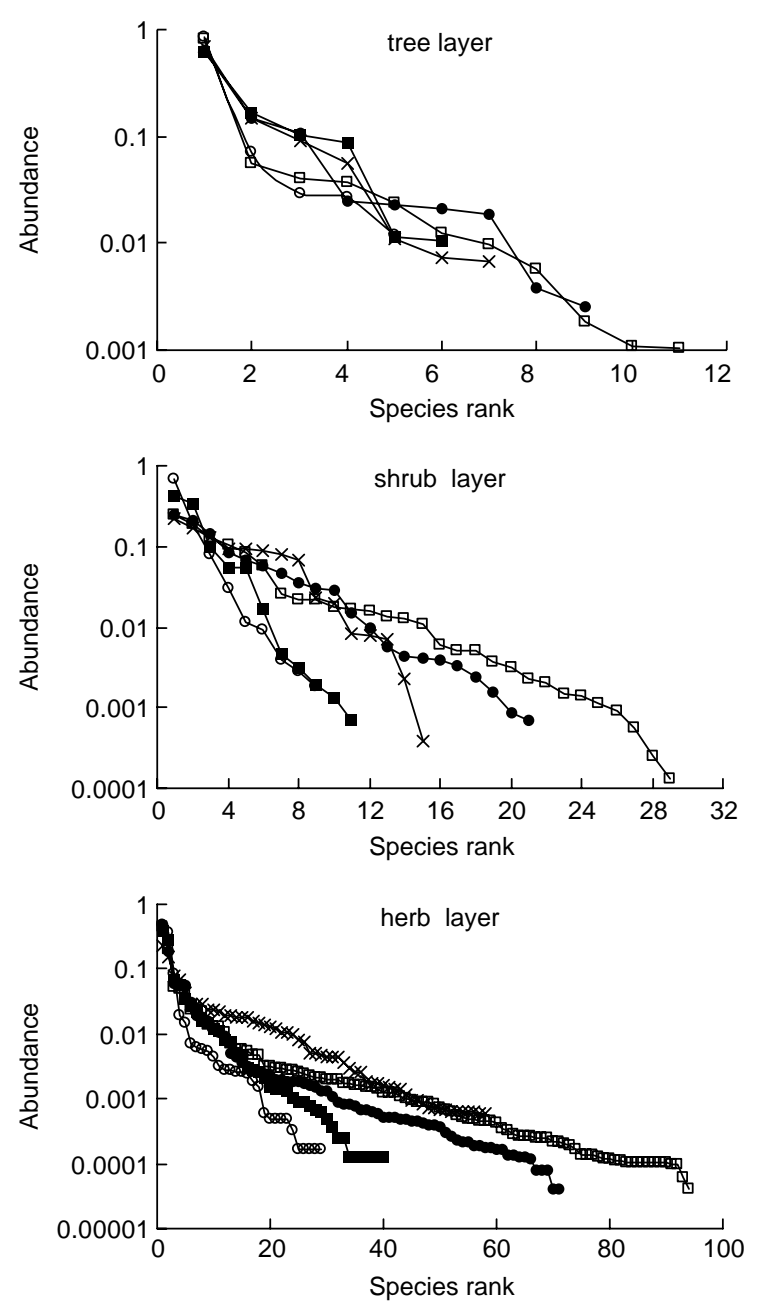

Fig. 2. Examples of rank-abundance curves of tree, shrub, and herb layers at different sampling size $(\delta) . \bigcirc-\delta=20 \times 10 \mathrm{~m}$; - $-\delta=40 \times 10 \mathrm{~m} ; \quad \times-\delta=80 \times 10 \mathrm{~m} ;-\quad-\delta=160 \times 10 \mathrm{~m}$; $\square-\delta=320 \times 10 \mathrm{~m}$.

tree and herb layers, but not as much in the shrub layer; similarity among scales is not obvious from this representation. Fig. $3 \mathrm{a}-\mathrm{c}$ show the species richness patterns along transect. Species richness can be seen to have a similar pattern among scales, but only at larger sampling scales, do we see a gradient trend emerging. Fig. 3d shows the classical species-area curves $(q=0)$ of different layers, the double-log plot is shown in Fig. 4.

Capacity dimension $\left(\mathrm{D}_{0}\right)$ (species richness scaling exponent), entropy dimension $\left(\mathrm{D}_{1}\right)$ (Shannon diversity index scaling exponent), and correlation dimension $\left(\mathrm{D}_{2}\right)$ (Simpson diversity scaling exponent) are selected as the examples of linear fitting in Fig. 4. In the tree layer, $q=0$ and $\mathrm{q}=1$ have good linear fit, while for $\mathrm{q}=2, \mathrm{r}^{2}=$ $0.7381<0.9$, and $\mathrm{p}=0.00145>0.001$; the corresponding dimension values are $\mathrm{D}_{0}=0.3695, \mathrm{D}_{1}=0.0755, \mathrm{D}_{2}=$ 0.0205 , and $\mathrm{D}_{1} / \mathrm{D}_{0}=0.2043$. In the shrub layer linear 

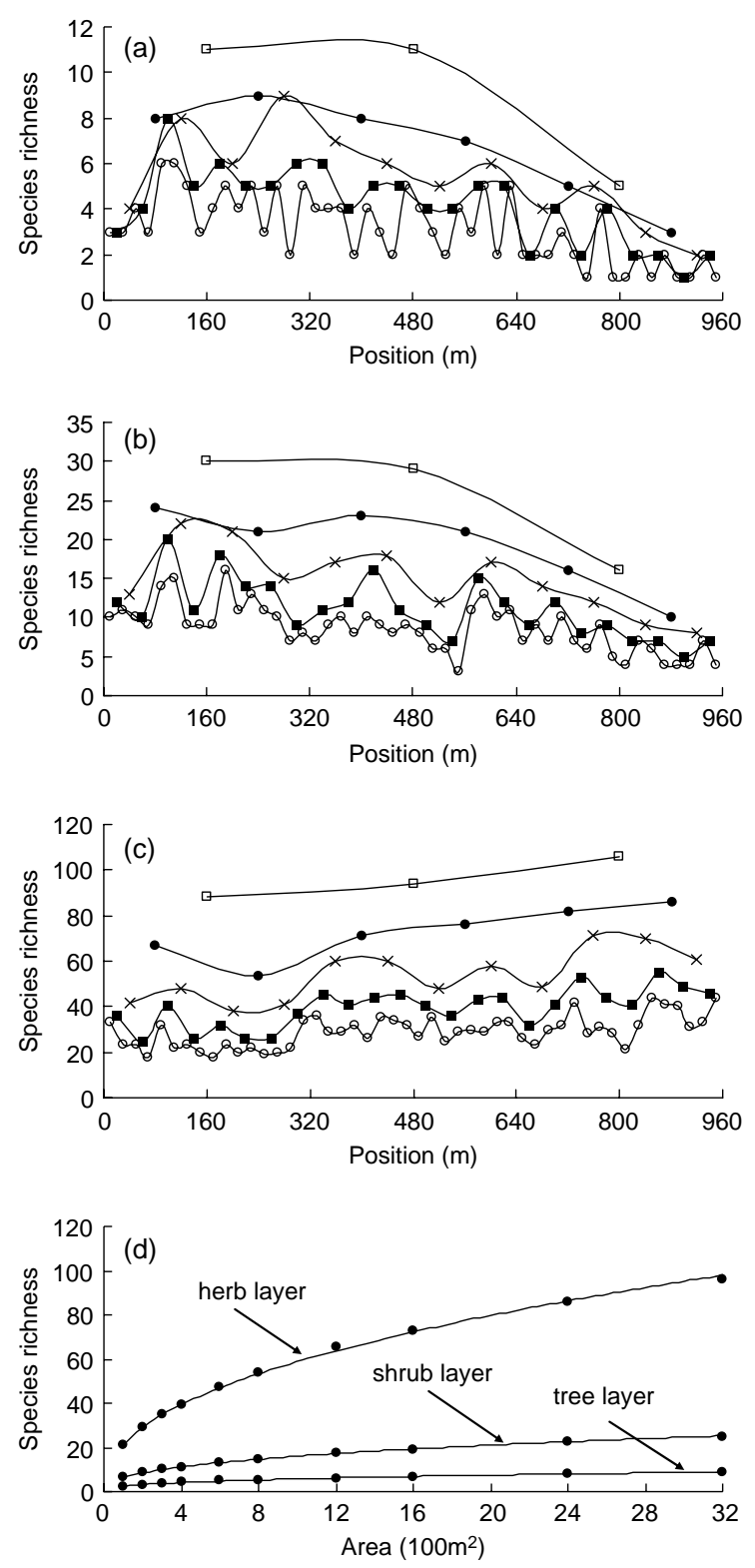

Fig. 3. (a), (b), (c) examples of species richness vary along transect of tree, shrub, and herb layers; $\bigcirc-\delta=20 \times 10 \mathrm{~m}$; $\square-\delta=40 \times 10 \mathrm{~m} ; \quad \times-\delta=80 \times 10 \mathrm{~m} ; 0-\delta=160 \times 10 \mathrm{~m} ;$ $\square-\delta=320 \times 10 \mathrm{~m}$. (d) The corresponding species - area curves of tree, shrub, and herb layers.

fitting for $\mathrm{q}=0,1,2$ show good fits $\left(\mathrm{r}^{2}>0.95, \mathrm{p}<0.001\right)$, with corresponding dimension values $\mathrm{D}_{0}=0.3838, \mathrm{D}_{1}=$ $0.2274, \mathrm{D}_{2}=0.1916$, and $\mathrm{D}_{1} / \mathrm{D}_{0}=0.5926$. In the herb layer $\mathrm{q}=0,1,2$ show good fits $\left(\mathrm{r}^{2}>0.95, \mathrm{p}<0.001\right)$, with corresponding dimension values $\mathrm{D}_{0}=0.4428, \mathrm{D}_{1}=$ $0.1544, \mathrm{D}_{2}=0.0902$, and $\mathrm{D}_{1} / \mathrm{D}_{0}=0.3488$. The rank of $\mathrm{D}_{1} / \mathrm{D}_{0}$ is shrub layer $>$ herb layer $>$ tree layer indicating that the species abundance distribution in shrub layer is more homogeneous than in herb and tree layers.
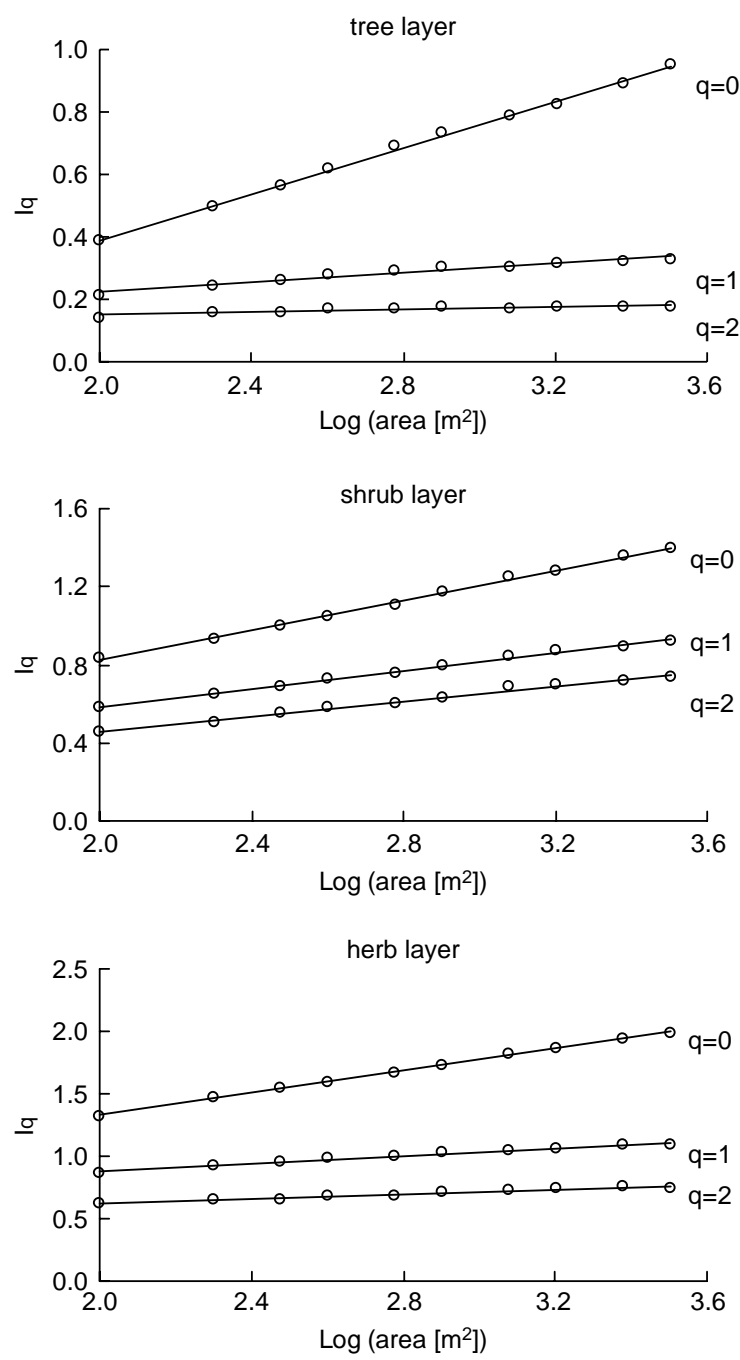

Fig. 4. Examples of Rényi entropy $\mathrm{I}_{\mathrm{q}}$ plot against $\log$ (area) for $\mathrm{q}=0$ (richness), $\mathrm{q}=1$ (Shannon), and $\mathrm{q}=2$ (Simpson) of tree, shrub, and herb layers. $r^{2}$ is coefficient of determination from linear regression fitting, $\mathrm{p}$ is significant value, the slope of the line is the estimate for the scaling exponent of the respective diversity-area power law relationship. Tree layer: $q=0, y=$ $0.3494+0.3695 \mathrm{x}, \quad \mathrm{r}^{2}=0.9980, \quad \mathrm{p}<0.001 ; \mathrm{q}=1, \quad \mathrm{y}=0.0728+$ $0.0755 \mathrm{x}, \quad \mathrm{r}^{2}=0.9557, \mathrm{p}<0.001 ; \mathrm{q}=2, \mathrm{y}=0.1089+0.0205 \mathrm{x}$, $\mathrm{r}^{2}=0.7381, \mathrm{p}=0.00145$. Shrub layer: $\mathrm{q}=0, \mathrm{y}=0.0541+$ $0.3838 \mathrm{x}, \mathrm{r}^{2}=0.9974, \mathrm{p}<0.001 ; \mathrm{q}=1 \mathrm{y}=0.1294+0.2274 \mathrm{x}, \mathrm{r}^{2}=$ $0.9947, \mathrm{p}<0.001 ; \mathrm{q}=2, \mathrm{y}=0.0747+0.1916 \mathrm{x}, \mathrm{r}^{2}=0.9885, \mathrm{p}<$ 0.001 . Herb layer: $\mathrm{q}=0, \mathrm{y}=0.4409+0.4428 \mathrm{x}, \mathrm{r}^{2}=0.9990, \mathrm{p}<$ $0.001 ; \mathrm{q}=1, \mathrm{y}=0.5666+0.1544 \mathrm{x}, \mathrm{r}^{2}=0.9892, \mathrm{p}<0.001 ; \mathrm{q}=2$, $\mathrm{y}=0.4422+0.0902 \mathrm{x}, \mathrm{r}^{2}=0.9778, \mathrm{p}<0.001$.

Complete multifractal Rényi spectra $\mathrm{D}_{\mathrm{q}}-\mathrm{q}$ curves of tree, shrub, and herb layers are shown in Fig. 5. In the tree layer, there are only two points which are significant at $\mathrm{p}>0.001(\mathrm{q}=2$ and $\mathrm{q}=2.5$ as shown in different symbols in Fig. 5 tree layer), however the two points are close to being significant ( $\mathrm{p}=0.00145$ and 0.00168$)$. For the shrub and herb layers, the coefficients of determination are high $\left(\mathrm{r}^{2}>0.90\right)$ and significant $(\mathrm{p}<0.001)$ for all 

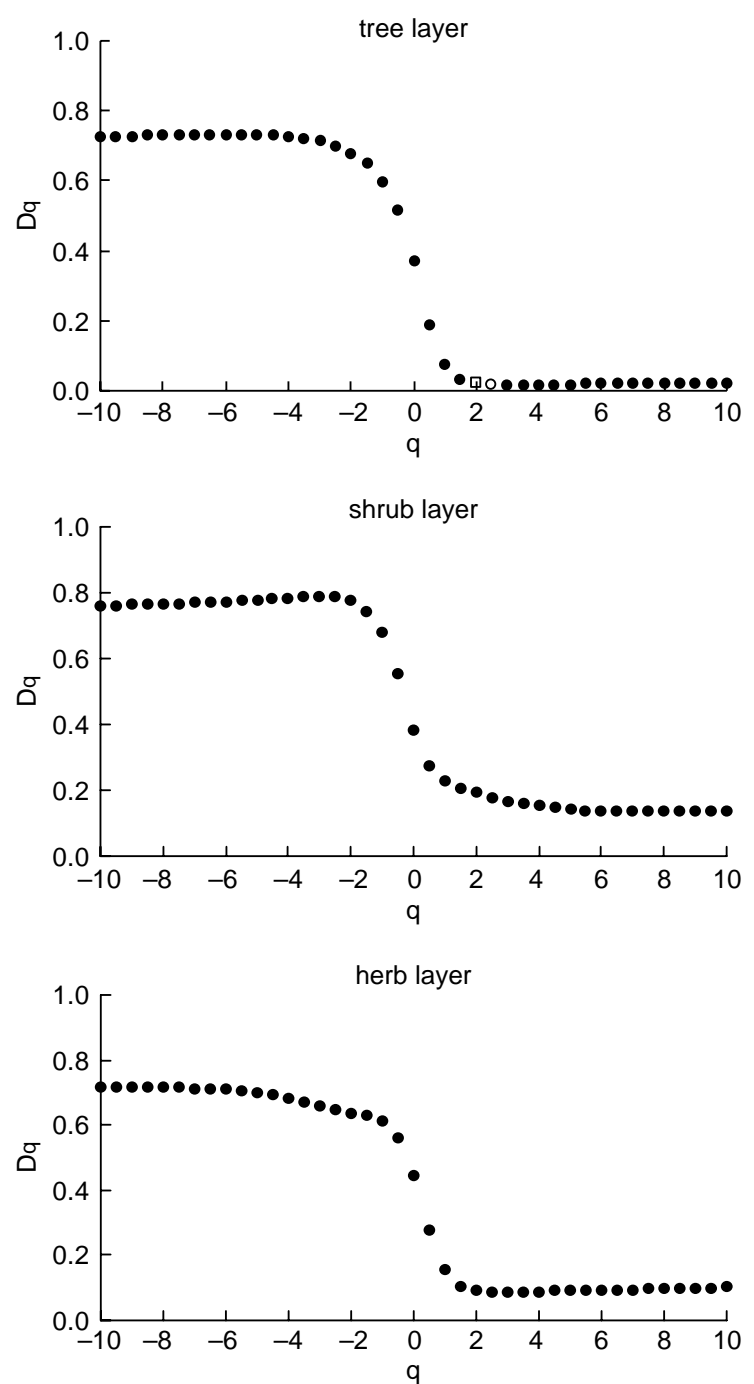

Fig. 5. Multifractal Rényi spectra $D_{q}-q$ curves of tree, shrub, and herb layers. $\square-q=2$, significant value $p=0.00145$; $\bigcirc-q=2.5$, significant value $\mathrm{p}=0.00168$; - significant value $\mathrm{p}<0.001$. Each point on these graphs is determined from a linear fitting as illustrated in Fig. 4.

q. Rényi spectra show slightly different shapes for the different layers, but all have sigmoid form (Fig. 5). In the tree layer, the maximum value of $\mathrm{D}_{\mathrm{q}}$ is $0.7329(\mathrm{q}=-10)$ and the minimum value is $0.0160(\mathrm{q}=3)$; In the shrub layer, the maximum value of $\mathrm{D}_{\mathrm{q}}$ is $0.7890(\mathrm{q}=-3)$ and the minimum value is $0.1346(\mathrm{q}=8)$; In herb layer, the maximum value of $\mathrm{D}_{\mathrm{q}}$ is $0.7196(\mathrm{q}=-10)$ and the minimum value is $0.0868(\mathrm{q}=3)$.

\section{Discussion}

Although the detailed properties of species abundance distribution patterns at relatively small scales may be drastically different from those measured at relatively large scales (Fig. 2, 3a-c), there are extensions of areas and ranges of scales where the patterns are statistically self-similar (Scheuring and Riedi 1994). We show that scaling laws exist not only for species richness as has been previously demonstrated by numerous other studies, but that it also occurs for other diversity indices. The power law behavior is shown by the well-known Shannon diversity (Fig. $4 \mathrm{q}=1$ ) and Simpson diversity (Fig. $4 \mathrm{q}=2$ ) area relationships, but also for higher-order Rényi entropy dimensions. To our knowledge, this is the first report of such robust scaling relationships in the species abundance distribution; we believe this pattern deserves to be explored further in other communities.

We found that the entropy dimension/capacity dimension ratio $D_{1} / D_{0}$, is an effective index to reflect the composition structure of different ecological assemblages (Fig. 4). The $D_{1} / D_{0}$ ratio is actually well-known as the evenness index of an ecological assemblage which represents the heterogeneity of the species abundance distribution (Pielou 1975, Magurran 1989), but to date, this index was restricted to a single scale analysis. In our work, $\mathrm{D}_{1} / \mathrm{D}_{0}$ ratio incorporates scale issues, and extends to cross-scale analysis.

In general, $\mathrm{D}_{\mathrm{q}}$ is a non-increasing function of $\mathrm{q}$ (Peitgen et al. 1992). But $D_{q}$ is not strictly a decreasing function of $q$ in our results. One possible explanation is that the linear regression method causes the problem (Cutler 1991, Halley et al. 2004). In addition, two points are not remarkably significant in tree layer distribution; this may come from the box-counting multifractal method, which is very sensitive to grid unit spatial resolution (Appleby 1996) and thus sampling size may not have been large enough for tree layer. Another reason maybe that Quercus liaotungensis is dominant species in tree layer but its abundance might not always high enough for the analysis. Comparing the difference between the multifractal spectra is beyond the extent of our work, but further work on such problems deserve consideration, because it could shed further light on linking assembly rules to different assemblages.

There are obviously several differences between our work and that of Borda-de-Água et al. (2002) who also attempted to fit multifractal Rényi spectra to speciesarea relationships: (1) a different forest type. Our work was conducted in a deciduous broad-leaved forest, while their work in a rainforest. (2) A different temperature zone. Our work was conducted at a warm temperate zone, while their work at neo-tropical temperate zone. (3) Extension to understory plant species of the forest. Their work only analyzed the woody species (trees and shrubs) of the forest, while our work analyzed trees, shrubs, and herbs respectively. (4) Different sampling method. They use a large quadrat plot (50 ha in area), while we used a transect (960 $\mathrm{m}$ in length, $10 \mathrm{~m}$ in width). In the herb 
layer, we use pooled small discrete plots $(31 \times 1 \mathrm{~m}$ plots pooled together representing $10 \times 10 \mathrm{~m}$ sampling unit for analysis). (5) Presence of gradients. Our work was conducted in a mountainous region with elevational gradients (the altitude range from $1110 \mathrm{~m}$ to $1735 \mathrm{~m}$ ) and climate gradients (according to a statistic geoclimate model (Jiang et al. 1994), there are $5-6^{\circ} \mathrm{C}$ in average annual temperature and $150-200 \mathrm{~mm}$ in annual precipitation gradient exist in the transect), while their work was conducted in a nearly flat ground (Condit et al. 2000). The first three points imply that we accomplished one purpose of our work which was to provide evidence of the hypothesis that scaling laws exist for species abundance distribution in a different forest type, a different temperate zone, and also in different plant assemblages.

However, we highly emphasize the last two points in our work. Using a small plot to predict diversity at large scale has very significant value, for it is more time saving. Small discrete plot has been used for extrapolating species richness from relative small spatial scale to large spatial scale (Harte et al. 1999b, Plotkin et al. 2000, Krishnamani et al. 2004), and in our work this method can also be done for the species abundance distribution analysis (Fig. 5, herb layer). Transect sampling is commonly used method for sampling ecological systems, and may be thought as a long, narrow rectangle plot sample. The effect of plot shape on ecological research is still an arguable issue (Keeley and Fotheringham 2005), despite the fact that it has been previously shown that transect or narrow rectangle plots are more effective than quadrat plot (Bormann 1953, Condit et al. 1996, Laurance et al. 1998). The transect sampling is very suitable and operable for elevational gradients analysis in our work, for one reason is that it is the most feasible (in time and cost) sampling method. Another possible reason maybe the transect method is one-dimensional analysis which can avoid the complexity of spatial asymmetry and autocorrelation compare with twodimensional analysis on BCI plot (Borda-de-Água et al. 2002).

The most intriguing thing about the robustness of our results is that we conducted our work in an ecosystem with an elevational gradient. Mountain topography can be considered closely analogous to the heterogeneous environments of land surface (Körner 2000). Inventories of biological organisms do not require the visitation of every square kilometer of mountain landscape (Körner et al. 2001). In elevation gradients, climate variables change more rapidly than along latitudinal gradients (Walter 1979). The results of our work suggest that despite the presence of a strong gradient, the scaling laws of species abundance distribution persist. Mountains may hold the answer for the forming mechanism of the biodiversity pattern (Körner et al. 2001), and our work gives a possible yet not final answer to the generality of the existence of scaling laws for species abundance distribution.

Acknowledgements - This research was supported by National Natural Science Foundation of China (Project 30470315 to Keming Ma and Project 40311101 to Bojie Fu), by Field Research Station Foundation of Chinese Academy of Sciences (to Keming Ma), and by the Natural Sciences and Engineering Research Council of Canada (NSERC) (to Madhur Anand) and the Canada Research Chairs Program (to Madhur Anand). We thank: Xincheng Liu, Jieyu Zhang, Jian Qi, Bing Xia, Liang Zhou, Ming Jin, Haihua Wang, Houjun Tang, Sha Huang and Jianlei Zhuang who have contributed substantially to the completion of the field investigation.

\section{References}

Alatalo, R. V. 1981. Problems in the measurement of eveness in ecology. - Oikos 37: 199-204.

Appleby, S. 1996. Multifractal characterization of the distribution pattern of the human population. - Geogr. Anal. 28: $147-160$

Arrhenius, O. 1921. Species and area. - J. Ecol. 9: 95-99.

Auerbach, M. and Shmida, A. 1987. Spatial scale and the determinants of plant species richness. - Trends Ecol. Evol. 2: $238-242$.

Borda-de-Água, L., Hubbell, S. P. and McAllister, M. 2002. Species-area curves, diversity indices, and species abundance distributions: a multifractal analysis. - Am. Nat. 159: $138-155$.

Bormann, F. H. 1953. The statistical efficiency of sample plot size and shape in forest ecology. - Ecology 34: 474-487.

Brown, J. H., Gupta, V. K., Li, B. L. et al. 2002. The fractal nature of nature: power laws, ecological complexity and biodiversity. - Philos. Trans. R. Soc. B 357: 619-626.

Caniego, J., Martín, M. A. and San José, F. 2003. Rényi dimensions of soil pore size distribution. - Geoderma 112: $205-216$.

Chen, L. Z. 1997. The importance of Donglingshan mountain region in warm temperate zone deciduous broad-leafed forests. - In: Chen, L. Z. (ed.), Study on the structure and function of forest ecosystem in warm temperate zone (in Chinese). Chinese Science Press, Beijing, pp. 1-9 (in Chinese).

Condit, R., Ashton, P. S., Baker, P. et al. 2000. Spatial patterns in the distribution of tropical tree species. - Science 288: $1414-1418$.

Condit, R., Hubbell, S. P., Lafrankie, J. V. et al. 1996. Speciesarea and species-individual relationships for tropical trees: a comparison of three 50-ha plots. - J. Ecol. 84: 549562.

Cutler, C. D. 1991. Some results on the behavior and estimation of the fractal dimensions of distributions on attractors. - J. Stat. Phys. 62: 651-708.

FAO-UNESCO (1988). Soil map of the world, revised legend. - World Soil Resour. Rep. 60, Rome.

Gaston, K. J. and Blackburn, T. M. 2000. Pattern and process in macroecology. - Blackwell Science.

Gaston, K. J. 1994. Rarity. - Chapman \& Hall.

Gaston, K. J. 2000. Global patterns in biodiversity. - Nature 405: $220-226$.

Halley, J. M., Hartley, S., Kallimanis, A. S. et al. 2004. Uses and abuses of fractal methodology in ecology. - Ecol. Lett. 7: $254-271$.

Harte, D. 2001. Multifractals: theory and applications. - Chapman \& Hall/CRC.

Harte, J., Conlisk, E., Ostling, A. et al. 2005. A theory of spatial structure in ecological communities at multiple spatial scales. - Ecol. Monogr. 75: 179-197. 
Harte, J., Kinzig, A. and Green, J. 1999a. Self-similarity in the distribution and abundance of species. - Science 284: 334 336.

Harte, J., McCarthy, S., Taylor, K. et al. 1999b. Estimating species-area relationships from plot to landscape scale using species spatial-turnover data. - Oikos 86: 45-54.

He, F. L. and Legendre, P. 1996. On species-area relations. - Am. Nat. 148: 719-737.

Hentschel, H. G. R. and Procaccia, I. 1983. The infinite number of generalized dimensions of fractals and strange attractors. - Physica D 8: 435-444.

Hill, M. O. 1973. Diversity and evenness: a unifying notation and its consequences. - Ecology 54: 427-432.

Hubbell, S. P. 2001. The unified neutral theory of biodiversity and biogeography. - Princeton Univ. Press.

Jiang, H., Huang, J. H., Chen, L. Z. et al. 1994. DCA ordination, quantitative classification and environmental interpretation of plant communities in Dongling Mountain. - Acta Bot. Sin. 36: 539-551 (in Chinese).

Kapos, V., Rhind, J., Edwards, M. et al. 2000. Developing a map of the world's mountain forests. - In: Price, M. F. and Butt, N. (eds), Forests in sustainable mountain development: a state-of-knowledge report for 2000. IUFRO Series No. 5. Wallingford, UK, CAB International, pp. 4-9.

Keeley, J. E. and Fotheringham, C. J. 2005. Plot shape effects on plant species diversity measurements. - J. Veg. Sci. 16: 249 256.

Körner, C. 2000. Why are there global gradients in species richness? Mountains might hold the answer. - Trends Ecol. Evol. 15: 513-514.

Körner, C., Spehn, E. and Messerli, B. 2001. Mountain biodiversity matters: executive summary of the global mountain biodiversity assessment conference 2000, RigiKaltbad, Switzerland. - Global Mountain Biodiversity Assessment (GMBA), Inst. of Botany, Univ. of Basel.

Kravchenko, A. N., Boast, C. W. and Bullock, D. G. 1999. Multifractal analysis of soil spatial variability. - Agron. J. 91: 1033-1041.

Krishnamani, R., Kumar, A. and Harte, J. 2004. Estimating species richness at large spatial scales using data from small discrete plots. - Ecography 27: 637-642.

Laurance, W. F., Ferreira, L. V., Rankin-De Merona, J. M. et al. 1998. Influence of plot shape on estimates of tree diversity and community composition in central Amazonia. - Biotropica 30: 662-665.
Lyons, S. K. and Willig, M. R. 1999. A hemispheric assessment of scale dependence in latitudinal gradients of species richness. - Ecology 80: 2483-2491.

Magurran, A. E. 1989. Ecological diversity and its measurement. - Croom Helm, London.

May, R. M. 1975. Patterns of species abundance and diversity. - In: Cody, M. L. and Diamond, J. M. (eds), Ecology and evolution of communities. Belknap Press, pp. 81-120.

Milne, B. T. 1991. Lessons from applying fractal models to landscape patterns. - In: Turner, M. G. and Gardner, R. H. (eds), Quantitative methods in landscape ecology. SpringerVerlag, pp. 199-239.

Montero, E. 2005. Rényi dimensions analysis of soil particlesize distributions. - Ecol. Modell. 182: 305-315.

Niklas, K. J. 1994. Plant allometry: the scaling of form and process. - Univ. of Chicago Press.

Orlóci, L. 1991. Entropy and information. Ecological computations series, vol. 3. - SPB Academic Publishing, The Hague, Netherlands.

Ostling, A., Harte, J., Green, J. L. et al. 2003. A communitylevel fractal property produces power-law species-area relationships. - Oikos 103: 218-224.

Ostling, A., Harte, J., Green, J. L. et al. 2004. Self-similarity, the power law form of the species-area relationship, and a probability rule: a reply to Maddux. - Am. Nat. 163: 627633.

Pachepsky, E., Crawford, J. W., Bown, J. L. et al. 2001. Towards a general theory of biodiversity. - Nature 410: 923-926.

Peitgen, H., Jürgens, H. and Saupe, D. 1992. Chaos and fractals. - Springer.

Pielou, E. C. 1975. Ecological diversity. - John Wiley and Sons.

Plotkin, J. B., Potts, M. D., Yu, D. W. et al. 2000. Predicting species diversity in tropical forests. - Proc. Natl Acad. Sci. USA 97: 10850-10854.

Preston, F. W. 1962. The canonical distribution of commonness and rarity: part I. - Ecology 43: 185-215.

Rahbek, C. 2005. The role of spatial scale and the perception of large-scale species-richness patterns. - Ecol. Lett. 8: 224239.

Rényi, A. 1970. Probability theory. - North-Holland, Amsterdam.

Scheuring, I. and Riedi, R. H. 1994. Application of multifractals to the analysis of vegetation pattern. - J. Veg. Sci. 5: 489-496.

Walter, H. 1979. Vegetation of the earth. - Springer. 